\title{
Editorial
}

\section{Emerging Economies Open Unlimited Opportunities for Advancing Management and Organization Scholarship}

\section{Arie Y. Lewin}

Duke University, USA

To follow Anne Tsui, the founder of the International Association for Chinese Management Research (IACMR) and the founding Editor-in-Chief of Management and Organization Review $(M O R)$, is an honor and a privilege as well as a most daunting challenge. However, as many colleagues of Anne know too well, it is almost impossible to turn down a request from her. She has sacrificed of herself to build the IACMR, and in nine short years has created a jewel of a specialized academic management journal. In many ways, MOR ranks among top management journals, and it has recently been listed by the Australian Business Deans Council as an 'A' journal.

In accepting the invitation to become the next Editor in Chief of $M O R$, I wanted to both continue building on the foundation that Anne and her team achieved while also amplifying the scope of the journal into the next generation. Therefore, I outlined several goals. First, to broaden the editorial coverage of the journal while reinforcing its rigor and relevance. Second, to broaden the context of the journal to include all emerging economies while maintaining the focus on China, as well as reinforcing the unique mission of mentoring and guiding China's faculty's and advanced $\mathrm{PhD}$ students' research and publishing capabilities. It is my hope that the combination of these will help the journal both solidify its position and develop and capture a new level.

The new editorial organization of $M O R$ encompasses two Deputy Editors (Professor Kwok Leung for micro organizational behavior, and Professor Klaus Meyer for macro organization theory and strategy and international business), twenty-six autonomous Senior Editors, a reorganized and expanded Editorial Review Board and a restructured manuscript submission system. The goal of these organizational changes is to diversify and broaden the scope of MOR's editorial reach. The overarching intent is to enhance the creative dynamism and intellectual risk-taking of $M O R$, and counteract natural tendencies toward creeping 
parochialism and homogenization of scholarship (March, 2005). The tendencies towards parochialism exist both within countries and within disciplines, so it is necessary to counter them on both levels.

West Churchman, as the first Editor in Chief of Management Science in 1954, created the decentralized departmental editorial structure of the journal. As one of the founders of the interdisciplinary field of Management Science, Churchman (1970) understood the importance of attracting multiple perspectives, and encouraging interconnectedness. The intention behind decentralizing editorial decisions to autonomous Senior Editors is to greatly increase the number of gatekeepers who attract, invite, and guide the review process of papers submitted to MOR and thereby increase the variety of papers submitted and published in $M O R$. Senior Editors are empowered to define, cultivate, and attract submissions and develop their unique editorial domain of the journal. Therefore, the editorial decisions of Senior Editors are binding on the journal and cannot be overruled by the Editorin-Chief. Given that $M O R$ has developed a reputation for its unique mentoring and developmental review process, the new MOR editorial team is committed to continue this practice by first finding the jewel in a paper (before finding reasons to reject the paper) and then guiding a deep, knowledgeable, and developmental review process. This commitment is being reinforced by limiting Senior Editors and their specific Editorial Review Board sub-group to handling a small number of manuscripts annually. The manuscript submission system has also been redesigned to maximize the match between the specific research focus of the submitted paper and the assignment of a Senior Editor and reviewers to the paper. The updated MOR Editorial Policy, new Senior Editor Structure, Editorial Review Board, and new manuscript submission policy can be found in this issue and on the IACMR website (http://www.iacmr.org).

In entrusting me to follow Anne as Editor-in-Chief, the IACMR board expressed the hope and the expectation that I would lead MOR to the next level. To me, that means $M O R$ will become the preferred management journal for submission of leading-edge scholarship; will give voice to shutting down, redirecting, or starting up new research agendas; will encourage empirically driven theory building; and will welcome scholarship that challenges the applicability of dominant theoretical doctrine (mostly originating in Western social science) to management and organizational phenomena in the context of emerging economies, their history, culture, and institutional configuration.

Special issues can serve to start up or redirect research agendas; the promise and potential of special issues will be assessed by MOR editors on the basis of the new MOR Research Frontiers Conference. The theme of the inaugural conference in Hong Kong on December 4-7, 2014, is 'The Globalization of Knowledge Creation and Innovation in the Context of Emerging Economies' (see the call for plenary session proposals in this issue). It is my fervent hope that the annual MOR Research Frontiers Cionference will serve as the formal 'exploration' strategy of 
MOR for identifying the bleeding edge of issues that $M O R$ can give voice to. I recognize that publishing papers that challenge established dominant theories or empirical approaches can be difficult in any discipline. MOR will continue to publish peer reviewed Perspective papers that set out to start up or redirect research agendas. However, there is also a need to give scholars and thought leaders an opportunity to share their 'out of the box' audacious and innovative ideas. Toward this end, $M O R$ is launching an editorial department intended to be controversial and to challenge the status quo. Momentum: Hopes for the Past; Lessons from the Future under the editorial leadership of Professor Mie Augier, will offer non-traditional treatment of themes relevant to the intellectual domain of $M O R$. It may feature interviews with leading scholars or business practitioners regarding issues of controversy, future scholarship, or practices relevant to MOR. Sec the Editorial Policies in this issue for more information about the upcoming Momentum section.

From its inception, one of $M O R$ 's editorial goals was to encourage publication of papers that elucidate indigenous Chinese management theory and practice. I believe that $M O R$ has a golden opportunity to contribute to the exploration of indigenous theories of management in the context of emerging economies. However, I also believe that progress requires an approach that builds on and extends universal concepts of individual and organization behavior. In what follows, I consider only one such line of thought, in the hope that it will rekindle and redirect research on indigenous theories of management.

Bounded and limited rationality (March \& Simon, 1958; Simon, 1947) is a widely accepted fundamental human condition that demarcates the limits of human information processing. One consequence of bounded rationality is that individuals and organizations make 'good enough' decisions, which March and Simon dubbed 'satisficing' decision making behavior (in contrast to optimizing). Bounded rationality underlies the empirical observation that designing and implementing organizations is the basis for accomplishing work activities that require marshalling the efforts of many individuals, technologies and diverse processes. However, in reality, it is always individuals (founders, entrepreneurs, managers, etc.) who architect, devise, implement, and restructure actual organizations. Moreover, these individuals act on the basis of their personalized theories of how to decompose work processes and tasks and create their organization (Caspin-Wagner \& Lewin, 2014; Heath \& Staudenmayer, 2000). Contrary to what I naively believed when I became the founding departmental editor in Management Science for the editorial department of Organizational Analysis and Organization Design (October 1974), the science of organization design is far from achieving the status of a universal normative or prescriptive discipline that managers can acquire and apply and that explains high variance attributable to firmspecfic effects in the emprical literature and the variation across national systems and cultures. 
Bounded rationality, satisficing, decomposing tasks to fit constraints of human information processing limitations, configuring organizations, and devising coordination and integration mechanisms are representative activities of any socioeconomic system, whether advanced or emerging. The fascinating theoretical and empirical challenge is to discover whether Chinese or other emerging economy managers devise and enact indiginous management solutions that are demonstrably different from managerial practices in developed economies as described in the vast extant body of management literature and managerial practice. In other words, do managers in emerging economies cope with consequences of bounded rationality by devising and implementing distinctly unique organization, structures, dynamic capabilities, management practices and routines? The variety of capitalism literature (e.g., Lewin \& Kim, 2004; Whitley, 1999) suggests that management practices and organizational designs both reflect and react to the national institutional configuration within which companies operate (Witt \& Lewin, 2007). Therefore, differences in the institutional configuration should moderate management practices across countries, especially when the journey from a low- to highendowment economy varies across emerging economies and across models of capitalism. Management theory and practice in the developed world has evolved since the Industrial Revolution. Management and organization design theories and practices in the emerging economies are still at an early stage of their industrialization journey.

Other sources of variation in management prcatices may be due to differences in cross-cultural communication behavior and the mediating role of embedded ambiguity in context-rich languages (e.g., Chinese, Korean, and Japanese), as well as the moderating effect of such dynamics as guanxi (Chen, Chen, \& Huang, 2013; Luo, Huang, \& Wang, 2012) or yin-yang (Fang, 2012; Jing \& Van de Ven, $2014 ; \mathrm{Li}, 2014)$. A variety of psychological processes - such as the nature of the mismatch that characterizes management intention and the evoked bahaviors of subordinates (e.g., the classic discussion in March \& Simon, 1958, and Heath \& Staudenmayer, 2000) - make it challenging to unpack such dynamics from the inherent ambiguity in any intra-organizational or inter-organizational communications processes.

In closing I wish to reiterate my commitment to carry on Anne's vision for $M O R$, to nurtue, guide, and lead $M O R$ to becoming recognized as an inclusive diverse interdisciplinary journal focused on publishing rigorous and relevant (Daft \& Lewin, 2008) management and organization scholarship.

A final change for the journal is that it will enter this new phase of its life with a new publisher. We are pleased to announce that starting in 2015 Cambridge University Press will become the publisher of Management and Organization Review on behalf of the International Association for Chinese Management Research. On behalf of Anne and the IACMR Board I wish to express our thanks and appreciation to Wiley-Blackwell for shepherding $M O R$ through its first 10 years. 


\section{REFERENCES}

Caspin-Wagner, K., \& Lewin, A. Y. 2014. Unpacking the black box of interdependencies fit. Working Paper, Fuqua School of Business.

Chen, C. C., Chen, X.-P., \& Huang, S. 2013. Chinese guanxi: An integrative review and new directions for future research. Management and Organization Revieze, 9(1): 167-207.

Churchman, C. W. 1970. Operations research as a profession. Management Science, 17(2): B37-BB53.

Daft, R. L., \& Lewin, A. Y. 2008. Rigor and relevance in organization studies: Idea migration and academic journal evolution. Organization Science Perspectives, 19(1): 177-183.

Fang, T. 2012. Yin yang: A new perspective on culture. Management and Organization Revieze, 8(1): 25-50.

Heath, C., \& Staudenmayer, N. 2000. Coordination neglect: How lay theories of organizing complicate coordination in organizations. Research in Organizational Behavior, 22: 155-193.

Jing, R., \& Van de Ven, A. 2014. A yin-yang model of organizational change: The case of CBG. Management and Organization Review, 10(1): 55-80.

Lewin, A. Y., \& Kim, J. 2004. The nation-state and culture as influences on organizational change and innovation. In M. S. Poole \& A. H. Van de Ven (Eds.), Handbook of organizational change and innovation: 324-353. Oxford: Oxford University Press.

$\mathrm{Li}, \mathrm{X} .2014$. Can yin-yang guide Chinese indigenous management research? Management and Organization Review, 10(1): 7-27.

Luo, Y., Huang, Y., \& Wang, S. L. 2012. Guanxi and organizational performance: A meta-analysis. Management and Organization Reviere, 8(1): 139-172.

March, J. G. 2005. Parochialism in the evolution of a research community: The case of organization studies. Management and Organization Review, l(1): 5-22.

March, J. G., \& Simon, H. A. 1958. Organizations. New York: John Wiley and Sons, Inc.

Simon, H. A. 1947. Administrative behavior: A study of decision-making processes in administrative organization. New York: The Macmillan Co.

Whitley, R. 1999. Divergent capitalism: The social structuring and change of business systems. Oxford: Oxford University Press.

Witt, M. A., \& Lewin, A. Y. 2007. Outward foreign direct investment as escape response to home country institutional constraints. Joumal of International Business Studies, 38: 579-594. 